\title{
ISSUES OF COTTON CELLULOSE AND ITS PROPERTIES AS AN OBJECT OF TECHNOLOGICAL PROCESSING
}

\author{
Kalibek Shamsiev ${ }^{1 *}$ \\ ${ }^{1}$ Tashkent state technical university named after Islam Karimov, Uzbekistan
}

\begin{abstract}
The main direction of these studies is the development of one of the promising drying methods - drying in swirling streams - for cotton cellulose, the demand for which in our country is very high. Thus, the total finished production of only two types of products: paper and fiber based on cellulosic raw materials - is about 140 million tons, which is approximately three times the volume of production of synthetic polymeric materials.
\end{abstract}

\section{Introduction}

Cellulose is found in many plant materials. However, it is never in their pure form. Of the large number of plant materials that have found application in the chemical industry, cotton linters are characterized by the highest cellulose content. Isolating cotton cellulose from linters is much easier than separating cellulose from wood, since linters contain up to $96 \%$ cellulose, and wood only $50 \%[1,2]$.

One example of increasing the water resistance of cellulose is esterification, in particular, surface acetylation of fibers. At the same time, actively interacting with water, the hydroxyl groups of cellulose are blocked by substitution with acetate groups, which are less vigorously solvated by water. That is why, for cotton cellulose intended for acetylation, one of the important factors is its reactivity after drying. The reactivity is influenced by the temperature of the coolant and its speed, the quality of material transportation inside the apparatus, the concentration of the material in the apparatus, and other factors [2, 3].

\section{Results and Discussion}

The study of the sorption properties of cotton cellulose is of great theoretical and practical interest, since it makes it possible not only to characterize the structural changes in the fiber, but also to find out the effect of sorted liquids, in particular water, on the chemical behavior, mechanical properties and electrical characteristics of cellulose. The hygroscopicity of cellulose is primarily associated with the structural features of its elementary units and the presence of hydroxyl groups in them [3, 4].

Cotton cellulose is a fibrous material that is composed of high molecular weight compounds. It is produced in the form of dense sheets, the weight of which reaches $400-600 \mathrm{~g}$ per $\mathrm{m}^{2}$, as well as in the form of a loose mass, the bulk density of which is $30-35$ $\mathrm{kg} / \mathrm{m}^{3}$. Sheets are used to obtain viscose fiber. When obtaining copper ammonia fiber or cellulose acetate, it is desirable to use cellulose in the form of a fibrous mass with a relatively high bulk density [3]. Some of the technical requirements for cotton cellulose used to obtain cellulose ethers are given below [2].

Appearance: loose mass, no compacted lumps.

Cleanliness: no foreign inclusions.

Color: pure white.

The transparency of the fiber solution in sulfuric acid: not established.

Viscosity: different depending on the brand of the product.

Humidity: no more than $8 \%$.

Content of $\alpha$-cellulose: not less than $99-99,5 \%$.

The degree of polymerization is $1500-1800$.

Wettability not less than $135 \mathrm{~cm}$.

The average fiber length is $2-3 \mathrm{~mm}$.

The content of insoluble residues in $\mathrm{H}_{2} \mathrm{SO}_{4}$ is not more than $0,3 \%$.

Ash content is not more than $0,1 \%$.

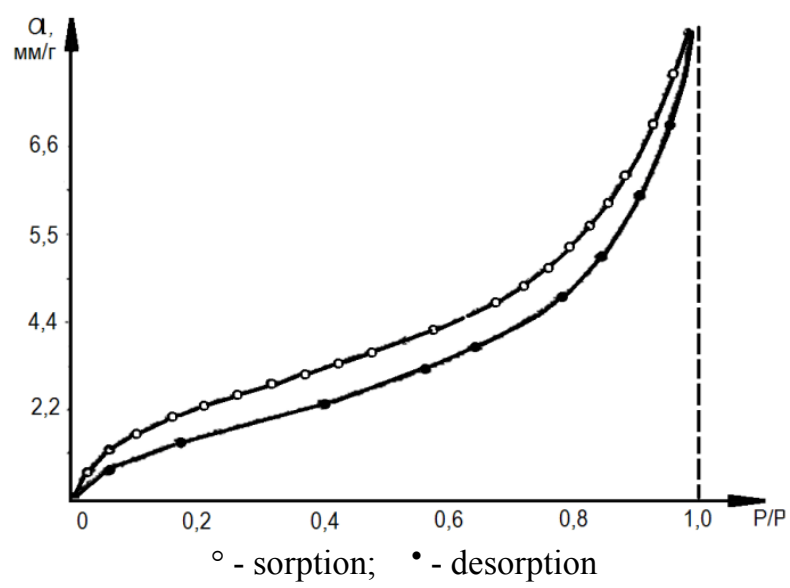

Fig.1. Isotherms of sorption and desorption of cotton cellulose at $t=25^{\circ} \mathrm{C}$.

We studied the sorption properties of cotton cellulose of various varieties of cotton fiber in different periods of

\footnotetext{
*Corresponding author: raxmatillo82@mail.ru
} 
vegetation (see Fig.1). On the basis of the obtained experimental data, isotherms of sorption - desorption of water vapor by cellulose were constructed. Sorption isotherm and desorption isotherm do not coincide in the entire range of relative pressures, they form a loop of sorption hysteresis, which means that cellulose is a limited swelling material, with a predominance of capillary condensation moisture [2, 5-7].

\begin{tabular}{|l|l|c|}
\hline \multicolumn{1}{|c|}{ Communication forms } & \multicolumn{1}{|c|}{ Types of communication 1} \\
\hline \multirow{2}{*}{ Physicochemical communication } & Moisture molecular adsorption & 3,41 \\
\cline { 2 - 3 } & Moisture polymolecular adsorption & $3,41-10$ \\
\hline \multirow{4}{*}{ Physicomechanical communication } & Capillary moisture of micropores & $10-18$ \\
\cline { 2 - 3 } & Butt moisture macropores & $18-25$ \\
\cline { 2 - 3 } & Moisture of the capillary state in the pores & $25-50$ \\
\cline { 2 - 3 } & Excess free water over the body & 50 \\
\hline
\end{tabular}

Based on the properties of cotton cellulose as an object of drying, it is possible to propose a method of drying it in one of the variants of a swirling heat carrier flow. In this case, a sufficiently high degree of activity of the hydrodynamic environment in the drying apparatus and a sufficient residence time of the material in it must be observed [4, 6, 8-9].

The advantage of a swirling flow in comparison with a direct flow is that it allows several times to increase the average relative velocity of the phases and to increase the concentration of solid material in the apparatus. Particles of solid material, due to the twist, constantly collide with the wall, as a result, the average speed of their movement does not exceed several meters per second [3, 10]. At a gas velocity of several tens of meters per second, the relative velocity of the gas and material reaches large values and is close to the velocities of the gas $[1,6,11]$.

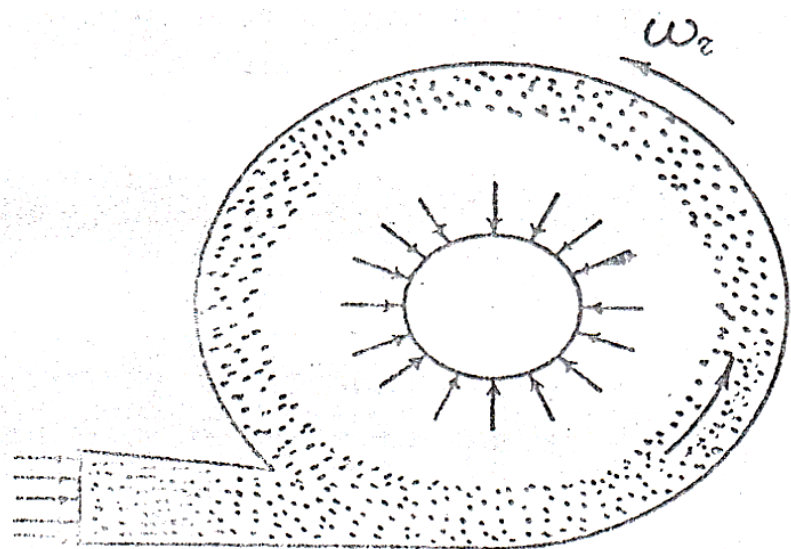

Fig.2. Modeling the motion of material particles in a vortex chamber

When describing the motion of the system "gas solid particles" in vortex dryers, it is of great importance to take into account the interaction of the gas and solid phases. This interaction, first of all, is expressed in the fact that the particles of the material take away part of the momentum from the gas, which leads to a decrease in the angular coordinate of the swirl of the gas flow [3$5,12]$.
For an additional study of the forms of moisturematerial connection, the thermogram method was applied.

Boundary moisture content in the materials under study, the types of moisture bonds are shown in Table 1 .
Experiments have shown that the form of the dependence of the tangential gas velocity $v \varphi$ on the current radius $r$ is extremal. $v \varphi$ with increasing $r$ first increases monotonically to its maximum value at the point $r=r_{r}$, then monotonically decreases to zero at $r=R$. The dependence $v_{\varphi}=v_{\varphi}(r, \varphi)$ is described by the expression [1-3, 13-14]:

$$
\begin{gathered}
A_{1}(\varphi) r^{\mathrm{n}} \text { at } r \leq r_{*} \\
v_{\varphi}(r, \varphi)=\{ \\
\mathrm{A}_{2}(\varphi) r^{-\mathrm{m}} \text { at } r \geq r_{*}
\end{gathered}
$$

The exponents " $n$ " and " $m$ " are found by the least squares method from the experimentally determined field of tangential components of the gas velocity $n=1,3$; $m=0,8[15]$.

At any point in the flow, the total velocity vector can be divided into three components: tangential $v_{\varphi}$, axial $v_{\mathrm{z}}$, and radial $v_{\mathrm{r}}$. In this case, the main motion of the gas in the apparatus is rotational. The speed $v_{\varphi}$ increases from the chamber wall to the center, reaching maximum values at some distance from the center. In accordance with the profile of the tangential velocity, it is customary to distinguish between two flow regions: peripheral and central. In the central zone, the distribution of the tangential velocity field is close to quasi-rigid rotation [4-8, 16-17]:

$$
v_{\varphi}=\omega \cdot r ;(\omega=\text { const })
$$

In the peripheral zone - close to potential:

$$
v_{\varphi}=\frac{\text { const }}{\mathrm{r}}
$$

In real vehicles, there is a transition zone between these two zones where the dependence of the tangential velocity on the radius is complex. The division of the quasi-rigid rotation zone and the potential zone is mainly qualitative. In general, in real devices, the dependence $v_{\varphi}=v_{\varphi}(r)$ in the central zone has the form $[3,11,18]$ :

$$
v_{\varphi} \sim r^{n}
$$

The change in the radial and axial velocity $\left(v_{\mathrm{r}}\right.$ and $\left.v_{\mathrm{z}}\right)$ along the radius of the vehicle also has a complex profile and may have several maxima and minima, which indicates the existence of currents along the axis and along the radius of the cyclone vehicles [19-22].

There are a number of dependencies for determining the components of the flow velocity vector based on certain assumptions of the flow motion mechanism [18- 
24] and including a number of coefficients determined experimentally.

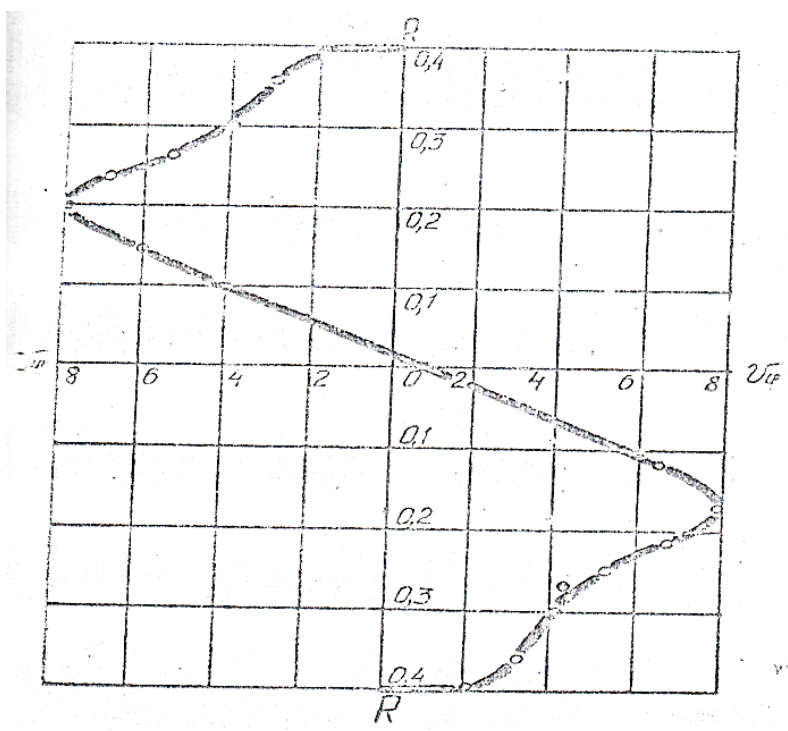

Fig.3. Tangential gas velocities over the section of the chamber
The level of velocity components in devices with swirling flows depends not only on the gas flow rates, but also on the geometric characteristics of the chambers: the radius of the device and the exhaust pipe, the total area of the inlet pipes, and the taper of the walls [20]. The location and extent of the characteristic flow zones can be described by dimensionless characteristics [1-3]:

$$
\frac{\mathrm{r}}{R} ; \frac{H}{P} ; \frac{v \varphi}{v_{\text {input }}} ; \frac{\mathrm{vz}}{v_{\text {input }}} ; \frac{\text { ur }}{v_{\text {input }}}
$$

where, $H$ - is the total hydrodynamic head, at this point; $P$ - full head at the chamber entrance.

To improve the swirl of the gas flow and more uniform loading of the vortex chamber over the material, a chamber with several tangential inlets can be used. It should be taken into account that in this case the production of the vortex chamber becomes more complicated. The experience of using the vortex chamber has shown that even for such a large chamber, one input is sufficient [1-3, 6-8].

The conducted studies of vortex chambers in laboratory and industrial conditions have revealed the following rational values of the regime - design parameters [4-6]

Table 1

\begin{tabular}{|l|c|}
\hline Input velocity of the gas flow vin, $\mathrm{m} / \mathrm{s}$ & $15 \div 20$ \\
\hline Consumable concentration of material Gm/Gr & $0,02 \div 0,04$ \\
\hline The ratio of the radius of the outlet to the radius of the chamber r/R & $0,6 \div 0,8$ \\
\hline The ratio of the width of the chamber to its diameter H/D & $0,3 \div 0,5$ \\
\hline Conditional radial gas velocity vr. $=\frac{L}{\pi D H}$ & $0,9 \div 1,2$ \\
\hline
\end{tabular}

Tests of experimental samples of a vortex chamber for preliminary processing of cotton cellulose of semiindustrial productivity showed that the processed material increases flowability and several times increases the storage period without spontaneous combustion [2128]. Swirl chambers offer a number of advantages over other swirl dryers. So, they have several times higher thermal power and productivity, the drying mode is soft, which allows them to dry finely porous materials with a high binding energy of moisture to a low residual moisture content, and the material is quickly removed from the drying zone, which guarantees the absence of overdrying, overheating of the material and changes in its physical and chemical properties. The advantages of the disk vortex chamber are also the simplicity of manufacture, compactness, and high efficiency [1-3, 22].

It should be noted that in most devices with swirling flows, the continuous and dispersed phases move in the same direction, and the residence time of the particle is small and poorly regulated. In some cases, despite the high intensity of heat and mass transfer processes, this time is not enough to remove moisture from materials that have a long drying period, this limits the scope of single-stage dryers [4-8]. Their disadvantages include the tendency to sticking when drying high-moisture foods. To a large extent, these disadvantages can be eliminated by using a vortex dryer for drying fibrous materials [6-7].
The advantage of disk vortex dryers is in a very active hydrodynamic mode, which is associated with a high level of relative velocities of gas and particles, controlled residence time of the material and the uniformity of its processing [3-4]. Disk vortex dryers are designed for a wide range of bulk and fibrous materials containing both free and bound moisture. The residence time of the material in the layer is several times longer than that of pipes with a screw insert [1-4].

\section{Conclusion}

The analysis made it possible to recommend a vortex chamber for drying cotton cellulose, characterized by both a high intensity of heat and mass exchange processes and a sufficient residence time of material particles in it.

\section{References}

1. S.Greg, K.Sing. Adsorbsiya, udelnaya poverxnost, poristost. Perevod s ang. - M.: Mir, - S.408, (1984).

2. V.I.Mushtaev, V.M.Ulyanov. Sushka dispersnix materialov (ISBN: 5-7245-0074-4). - M.: Ximiya, - S.352, (1988).

3. Shamsiyev K.S., Shamsiyeva N.K. Problemi energo- i resursosberejeniya (ISSN: 2091-5985), - Tashkent, 3-4, - S.166-168, (2016). 
4. Shamsiyev K.S., Shamsiyeva N.K. IJARSET (ISSN: 2350-0328), Vol.6, Issue 4, (2019).

5. Shamsiev K.S., Abdirova M.T., Shamsieva N.K., Umirzakov R.A. III International scientific and practical conference "Science and education in the modern world: challenges of the XXI century", Nur-Sultan, (2019).

6. Karimov R. Ch., Shamsiyev K., and others. IOP Conf. Series: Materials Science and Engineering, 2020, 883(1), 012142, doi:10.1088/1757-899X/883/1/012142

7. Karimov R. Ch., Shamsiyeva N., and others. IOP Conf. Series: Materials Science and Engineering, 2020, 883(1), 012120, doi:10.1088/1757-899X/883/1/012120

8. Rakhmonov, I. U., Reymov, K.M., Dustova, S.H. (2020) Improvements in industrial energy rationing methods Journal of IOP: Conference Series. MIP: $\begin{array}{llll}\text { Engineering-2020. } & 862 \quad \text { (2020) } & 062070\end{array}$ doi:10.1088/1757-899X/862/2/062070

9. Khushnud Sapaev and Shukhrat Umarov. Two approaches for automating analysis of electromagnetic processes in non-linear circuits with valves. Web of Conferences https://doi.org/10.1051/e3sconf/20191390 E 3S 139 (2019) 101085 RSES 20198

10. Usmanov E.G., Rasulov A.N., Bobojanov M.K., Karimov R.Ch. E3S Web of Conferences, 2019, 139, 01079, doi.org/10.1051/e3sconf/201913901079

11. Rismuhamedov D., Tuychiev F., and others. IOP Conf. Series: Materials Science and Engineering, 2020, 883(1), 012140. doi:10.1088/1757-899X/883/1/012140

12. Avezova N.R., Toshov J.B., Dalmuradova N.N., Farmonova A.A., Mardonova M.Sh.Renewable Energy: Scenario and Model of Development // ISSN 0003701X, Applied Solar Energy, 2019, Vol. 55, No. 6, pp. 438-445. DOI: 10.3103/S0003701X19060021

13. Mannanov U., Toshov J., Toshniyozov L. Perspective Solutions for the Design of Drilling Tools / E3S Web of Conferences 105, 03027 (2019) IVth International Innovative Mining Symposium, https://doi.org/10.1051/e3sconf/201910503027

14. Rasulov A.N., Karimov R.Ch. EESJ, №4, P.179-183 (2015), doi:10.12851/EESJ201508C05ART01

15. Toshov, Zh.B. Ways towards optimization of washout components of rock cutting tools Information about author // Gornyi Zhurnal. Volume 2016, Issue 2, 1 January 2016, Pages 21-24.

16. Burievich, T.J. The questions of the dynamics of drilling bit on the surface of well bottom// Arch. Min. Sci. -Poland. - Vol. 61 (2016). - №2. - P. 279-287. DOI 10.1515/amsc-2016-0020.

17. Toshniyozov, L.G., Toshov, J.B. Theoretical and experimental research into process of packing in drilling// Mining Informational and Analytical Bulletin Volume 2019, Issue 11, 2019, Pages 139-151. DOI: 10.25018/0236-1493-2019-11-0-139-151.

18. Rasulov A.N., Karimov R.Ch. EESJ, №4, P.174-178 (2015), doi:10.12851/EESJ201508C05ART02

19. Rakhmonov, I.U., Berdishev, A.A., Khusanov, B.M., Khaliknazarov, U., Utegenov, U. (2020) General characteristics of networks and features of electricity consumers in rural areas Journal of IOP: Conference Series. MIP: Engineering-2020. 883 (2020) 012104 doi: $10.1088 / 1757-899 X / 883 / 1 / 012104$
20. Karimov, R.Ch., Bobojanov, M.K., Rasulov, A.N., Usmanov, E.G. E3S Web of Conferences, 2019, 139, 01039, doi.org/10.1051/e3sconf/201913901039

21. Toshov J., Saitov E. Portable autonomous solar power plant for individual use / E3S Web Conf., Volume 139, 01087, 2019, Rudenko International Conference "Methodological problems in reliability study of large energy systems" (RSES 2019), https://doi.org/10.1051/e3sconf/201913901087

22. Azamatovich, A.N., Amrillo, M.B, Burievich, T.J., Umarxanoxich, J.R., Shavkatovich, Z.A. A complex of methods for analyzing the working fluid of a hydrostatic power plant for hydraulic mining machines / International Journal of Advanced Science and Technology. Volume 29, Issue 5 Special Issue, 28 March 2020, Pages 852-855

23. Hoshimov, F.A., Bakhadirov, I.I., Erejepov, M., Djumamuratov, B. (2019) Development of method for normalizing electricity consumption E3S Web Conf 139 doi:10.1051/e3sconf/201913901074

24. Rakhmonov, I.U., Berdishev, A.A., Niyozov, N.N., Muratov, A., Khaliknazarov U. (2020) Development of a scheme for generating the predicted value of specific electricity consumption Journal of IOP: Conference Series. MIP: Engineering-2020. 883 (2020) 012103 doi:10.1088/1757-899X/883/1/012103

25. Allayev, K.R., Fedorenko, G.M.,Postnikov, V.I.,Ostapchuk, L.B. Asynchronous generators as power system's natural dampers. 43rd International Conference on Large High Voltage Electric Systems 2010, CIGRE 20102010, 9p43rd International Conference on Large High Voltage Electric Systems 2010, CIGRE 2010; Paris; France; 22 August 2010.

26.Fazylov, Kh.F.,Allaev, K.R. Analysis of the operation of an electrical system during simultaneous operation of synchronous and asynchronous generators. Power engineering New York Volume 18, Issue 3, 1980, Pages 81-88.

27.Fazylov, Kh.F.,Allaev, K.R. Asynchronous turbogenerators with stator excitation and the prospects for their utilization. Power engineering New York Volume 23, Issue 2, 1985, Pages 7-13.

28.Fazylov, Kh.F.,Allaev, K.R. Calculation and experimental analysis of conditions of electrical power systems containing induction generators Power Engineering New York Volume 27, Issue 6, 1989, Pages 27-34. 